\title{
Transdisciplinaridade e interculturalidade: experiências vividas e compartilhadas no curso de educação intercultural indígena - UFG (2018)
}

\author{
Transdisciplinarity and interculturality: experiences lived and shared \\ in the indigenous intercultural education course - UFG (2018)
}

\section{Transdisciplinaridad $e$ interculturalidad: experiencias vividas $y$ compartidas en el curso de educación intercultural indígena - UFG}

(2018)

\section{Tamiris Maia Gonçalves Pereira ${ }^{1}$}

Universidade Federal de Goiás, Doutoranda em História pelo Programa de Pós-Graduação em História da Universidade Federal de Goiás

https://orcid.org/0000-0001-8175-256X

http://lattes.cnpq.br/8880569031234685

\section{Ordália Cristina Gonçalves Araújo²}

Universidade Estadual de Goiás, Universidade Federal de Goiás, Professora da Faculdade de História da Universidade Estadual de Goiás https://orcid.org/0000-0002-7585-0320

http://lattes.cnpq.br/9191051045071313

\section{Elias Nazareno ${ }^{3}$}

Universidade Federal de Goiás, Professor Associado I da Faculdade de História e do Curso de Educação Intercultural

https://orcid.org/0000-0002-9689-9721

http://lattes.cnpq.br/1486334927436240

Resumo: 0 presente artigo pretende apresentar os conceitos da "transdisciplinaridade" e da "interculturalidade crítica" que permearam as dinâmicas das aulas sobre o Tema Contextual Educação Intercultural Bilíngue e, sobretudo, evidenciar a contribuição dos estudantes indígenas em sala como representantes de suas epistemologias. Suas experiências apontaram para a importância de debates mais aprofundados em torno da diversidade, da diferença e da interculturalidade no contexto educacional brasileiro, discussão levantada a partir de três atividades didáticas propostas e realizadas durante as aulas, nas quais narrativas, textos escritos e documentos imagéticos foram desenvolvidos. As produções e reflexões foram fundamentadas nos princípios da "enação", "transdisciplinaridade", "interculturalidade

Mestre em História pela Pontificia Universidade Católica de Goiás; Doutoranda em História pela Universidade Federal de Goiás. Mestre em História pela Universidade Federal de Goiás; Doutoranda em História pela Universidade Federal de Goiás.

Doutor em Sociologia pela Universidade de Barcelona; Mestre em História pela Universidade de Brasília. 
crítica" (MATURANA, 2000; NASCIMENTO, 2014; VARELA; THOMPSON; ROSCH, 1992; WALSH, 2013; WALSH; VIAÑA; TAPIA, 2010) e em suas experiências educacionais. Ao analisarem seus conhecimentos e usos no cotidiano, os estudantes consideraram que, para além do conceito de "interculturalidade", cunhado na década de 1970, na América Latina, o chamado "intercâmbio entre povos" (termo rememorado por eles durante as aulas) já existia como prática, mesmo antes de ser utilizado nas poĺticas públicas, na atualidade.

Palavras-chave: Transdisciplinaridade. Interculturalidade. Tema contextual. Estudantes indigenas.

Abstract: The present article intends to present the concepts of "transdisciplinarity" and "critical interculturality" that permeated the dynamics of the classes on the Contextual Theme Intercultural Bilingual Education and, above all, to highlight the contribution of indigenous students in the classroom as representatives of their epistemologies. Their experiences pointed to the importance of deeper debates about diversity, difference and interculturality in the Brazilian educational context, a discussion based on three didactic activities proposed and carried out in class, in which narratives, written texts and documents images were developed. The productions and reflections were based on the principles of "enaction", "transdisciplinarity", "critical interculturality" (MATURANA, 2000; NASCIMENTO, 2014; VARELA; THOMPSON; ROSCH, 1992; WALSH, 2013; WALSH; VIAÑA; TAPIA, 2010) and their educational experiences. In analyzing their knowledge and uses in everyday life, students considered that in addition to the concept of "interculturality", coined in the 1970s in Latin America, the so-called "interchange between peoples" (term rememored by them during classes) already existed as a practice, even before being used in public policy, at present.

Keywords: Transdisciplinarity. Interculturality. Contextual theme. Indigenous students.

Resumen: El presente artículo pretende presentar los conceptos de la "transdisciplinariedad" y de la "interculturalidad crítica" que permearon las dinámicas de las clases sobre el Tema Contextual Educación Intercultural Bilingüe y, sobre todo, evidenciar la contribución de los estudiantes indigenas en el aula, como representantes de sus epistemologías. Sus experiencias apuntaron a la importancia de debates más profundizados en torno a la diversidad, la diferencia y la interculturalidad en el contexto educativo brasileño, discusión planteada a partir de tres actividades didácticas propuestas y realizadas durante las clases, en las que sus narrativas, textos escritos y documentos se han desarrollado. Las producciones y reflexiones fueron fundamentadas en los principios de la "enacción", "transdisciplinariedad", "interculturalidad crítica" (MATURANA, 2000; NASCIMENTO, 2014; VARELA; THOMPSON; ROSCH, 1992; WALSH, 2013; WALSH; VIAÑA; TAPIA, 2010) $y$ en sus experiencias educativas. Al analizar sus conocimientos y usos en el cotidiano, los estudiantes consideraron que además del concepto de "interculturalidad", propuesto en la década de 1970, en América Latina, el llamado "intercambio entre pueblos" (término rememorado por ellos durante las clases) ya existía como práctica, incluso antes de ser utilizado en las políticas públicas, en la actualidad.

Palabras clave: Transdisciplinariedad. Interculturalidad. Tema contextual. Estudiantes indígenas.

Recebido em 23 de maio de 2018

Aceito em 19 de março de 2019

Publicado em 16 de abril de 2019 


\section{INTRODUÇÃO}

0 presente artigo pretende apresentar os conceitos da "transdisciplinaridade" e da "interculturalidade crítica" que permearam as dinâmicas das aulas sobre um dos temas contextuais do Curso de Licenciatura em Educação Intercultural da Universidade Federal de Goís $^{4}$ com estudantes indígenas Alto Xinguanos (Kuikuro e Yawalapiti), Bororos, Guajajaras, Javaés, Karajás, Kayapós, Tapirapés, Timbiras (Krahô e Gavião), Xavantes e Xerentes. Trata-se do tema Educação Intercultural Bilíngue, ministrado em janeiro de 2018 como parte da Matriz de Formação Básica do Curso. ${ }^{5}$

A partir da experiência do Curso de Licenciatura Intercultural Indígena da Universidade Federal de Roraima (UFRR), os temas contextuais se tornaram uma estrutura fundamental do Projeto Politico Pedagógico (PPP) do Curso com perfil pedagógico similar ao oferecido pela Universidade Federal de Goiás (UFG), desde 2007, para atender estudantes indígenas das regiões Araguaia-Tocantins e do Xingu nos Estados de Goiás, Maranhão, Mato Grosso e Tocantins. ${ }^{6}$

Superando a noção de disciplina curricular, o tema contextual ${ }^{7}$ rejeita a compartimentação das diversas áreas do conhecimento em nome de um constante transbordamento das "fronteiras epistemológicas artificialmente criadas entre conhecimento prático e conhecimento teórico configurando-se como premissa fundamental para a criação ou ressurgimento de novas bases epistemológicas ou pluriepistemológicas de construção do saber." (NAZARENO; ARAÚJO, 2017, p. 120). Pautado pelo princípio da transdisciplinaridade e da interculturalidade crítica, o tema contextual implica, da mesma maneira, uma metodologia também contextual ao congregar uma série de atitudes e posicionamentos propostos pela decolonialidade e pela transdisciplinaridade.

$4 \quad 0$ Curso de Licenciatura em Educação Intercultural, da Universidade Federal de Goiás, está dividido em quatro etapas práticas de atividades: Estudos Presenciais, nos meses de férias escolares (janeiro/fevereiro e julho/agosto), e Estudos em Terras Indigenas (abril/maio e outubro/novembro). Durante todas as etapas de estudo, as atividades ocorrem semanalmente nos períodos matutino e vespertino.

50 currículo do Curso de Licenciatura Intercultural da Universidade Federal de Goiás constitui-se da Matriz de Formação Básica e das três Matrizes de Formação Específica (Ciências da Cultura, Ciências da Linguagem e Ciências da Natureza). Todas elas são compostas de temas referenciais (identidade, conflito, autonomia, alteridade, interculturalidade, sustentabilidade, diversidade e diferença) e temas contextuais básicos e específicos, de acordo com o Projeto Político-Pedagógico.

$6 \quad 0$ Curso de Licenciatura Intercultura Indígena da UFG atende estudantes dos seguintes povos: Apinajé, Canela, Gavião, Guajajara, Javaé, Juruna, Kalapalo, Kamaiurá, Karajá, Krahô, Krikati, Kuikuro, Mehinako, Tapirapé, Tapuia, Timbira, Xakriabá, Xambioá, Xavante, Xerente e Waura (NAZARENO, 2017).

7 A iniciativa pioneira do uso dos temas contextuais na educação foi realizada pelos propositores do Curso de Licenciatura Intercultural Indigena da Universidade Federal de Roraima (UFRR), em seu Projeto Político Pedagógico, entre os anos 2000 e 2003. De acordo com Repetto (2012, p. 18), "Iplropomos temas contextuais para questionar, para experimentar e pesquisar se é possível uma outra forma de estudar e de organizar o currículo. Os temas contextuais não são uma fórmula. Devem ser discutidos, adaptados, modificados e criticados. Os temas contextuais devem fazer uma leitura a partir da Interculturalidade." 
Compartilhamos a noção de transdisciplinaridade de Maldonado-Torres (2016, p. 93-94) que a compreende

como orientação e suspensão de métodos e disciplinas a partir da decolonização como projeto e como atitude. Esta atitude e este projeto são parte do que podemos chamar de consciência decolonial (decolonial consciousness), em contraposição à consciência moderna (modern consciousness). Enquanto a consciência moderna encarrega-se de afiançar as bases das linhas seculares e ontológicas moderno-coloniais, a consciência decolonial busca decolonizar, des-segregar e des-generar o poder, o ser e o saber (Maldonado-Torres, 2007a). Isto é feito ao criar laços e novas formas entre esferas que a Modernidade ajudou a separar: a esfera da política ou do ativismo social, a esfera da criação artística e a esfera da produção de conhecimento.

Já a interculturalidade crítica, na acepção de Walsh, Viaña e Tapia (2010) e Walsh (2013), é percebida como processo social, político e epistêmico e pode ser tomada como sinônimo de decolonialidade, pois denota o processo de resistência e de afirmação identitária vivenciado pelos povos indígenas brasileiros "que permanecem vivos, com seus conhecimentos e suas línguas." (NAZARENO, 2017, p. 46).

Nesse sentido, pretendemos evidenciar, sobretudo, a contribuição dos estudantes indígenas em sala de aula como representantes das epistemologias de seus povos. Ainda que limitadas pelo ambiente universitário, as experiências desses estudantes apontam para a importância e a necessidade do aprofundamento dos debates em torno da diversidade, da diferença e da interculturalidade em seus contextos educacionais. Seus questionamentos, relatos e inquietações foram evidenciados durante a realização de três atividades didáticas nas quais discutimos as práticas educacionais indígenas realizadas dentro e fora das escolas indígenas.

Na primeira atividade utilizamos o vídeo Our spirits don't speak English: Indian boarding school (Nossos espíritos não falam inglês: internato indígena), um documentário produzido em 2008 por Steven Heape e dirigido por Chip Richie nos Estados Unidos; e o artigo A formação de trabalhadores brasileiros: a experiência do Colégio Isabel, de Joel Orlando Bevilaqua Marin (2009), tendo em vista a realização de um debate sobre as propostas assimilacionistas voltadas para os povos indígenas em distintos contextos e épocas, que representaram os ideais cristianizadores e civilizadores por meio de projetos educativos pautados na negação da cultura ancestral e na imposição da cultura europeia. Buscamos, ademais, compreender suas opiniões sobre o assunto e suas atuações nas realidades de suas aldeias.

Na segunda atividade objetivamos a interpretação e a reflexão, por parte dos discentes, dos conceitos de "interculturalidade" e "transdisciplinaridade" a partir do artigo "Interculturalidade: apontamentos conceituais e alternativa para a educação bilíngue", de 
Nascimento (2014). Esse artigo foi trabalhado como texto-base para as discussões referentes à "interculturalidade", ao "multiculturalismo" e à "transdisciplinaridade" em sala de aula.

Por fim, a terceira e última atividade teve como objetivo principal retomar a reflexão sobre o conceito de "interculturalidade" apresentado no vídeo, nos textos e nos debates anteriores para que examinassem suas práxis nas aldeias. Em sua execução, os discentes reuniram-se em grupos e debateram a questão da existência de elementos culturais que pertencem a outros povos e que passaram a fazer parte de sua cultura, de forma impositiva ou não impositiva.

Além do documentário e das cópias dos artigos mencionados, os estudantes tiveram à disposição outros recursos, como cartolinas, pincéis para papel, tinta guache, pincéis para tinta guache, etc., para execução das atividades propostas, as quais se completaram com debates em grupo, produção de textos, confecção de desenhos, apresentações orais e apresentações de músicas e danças indígenas. Todo esse material foi registrado, constituindose em importante fonte para as reflexões a seguir.

Mediante esses esclarecimentos e tendo em vista que a interculturalidade e o bilinguismo foram centrais no estabelecimento das estratégias de lutas dos povos indígenas na América Latina na história da educação escolar indígena (CANDAU; RUSSO, 2010), o objetivo geral do tema contextual foi possibilitar uma visão mais aprofundada e crítica e menos essencialista dos conceitos, fundamentando, assim, uma práxis docente indígena crítica e descolonizadora.

\section{REFERENCIAL TEÓRICO E METODOLÓGıICO}

Nascimento (2014) apresenta uma revisão do conceito de interculturalidade desde uma perspectiva latino-americana e proposições na área educacional voltadas para povos racialmente subalternizados, como os indígenas brasileiros. Essa proposição emergiu no contexto constitucional de 1988, no qual se reconheceu o caráter pluricultural e multilíngue do Brasil, como contraponto ao discurso assimilacionista e integracionista.

Na perspectiva intercultural crítica proposta por Tubino (2004 apud NASCIMENTO, 2014, p. 8), "[...] há que se começar por recuperar a memória dos excluídos, por visibilizar os conflitos interculturais do presente como expressão de uma violência estrutural mais profunda, gestada ao longo de uma história de desencontros e postergações injustas." Em vista disso, a mudança de orientação nas políticas educacionais dos países latino-americanos, incluindo o Brasil, em finais de 1970 e início de 1980, decorrente das lutas implementadas por lideranças indígenas, intelectuais e professores, culminou na proposição de uma educação focada nas línguas e culturas próprias de cada povo. 
Um currículo bilíngue intercultural, tendo como base os conhecimentos indígenas em suas particularidades culturais e epistemológicas e nos conhecimentos não indígenas, passou a reconhecer a existência de conhecimentos distintos. Porém, ainda se faz necessária uma estratégia epistemológica decolonial que evidencie o diálogo interepistêmico entre distintas concepções de conhecimentos, sem propor relações hierárquicas entre elas ou torná-las universais (STELL; CARVALHO, 2014). A dimensão intercultural crítica propõe, dessa forma, a possibilidade de mudança de orientação a todo o sistema educativo oficial, incluindo populações indígenas e não indígenas. Trata-se, ainda, de um devir necessário, visto que para iniciá-lo é imprescindível que a sociedade dominante também mude.

As discussões sobre interculturalidade que pautaram o desenvolvimento das aulas foram guiadas pela dinamicidade, oralidade e "enação", ou seja, pelos processos cognitivos que ultrapassam a questão da escrita e da fala. Ocorre, sobretudo, pela interação da pessoa com o ambiente, por meio de todas as sensibilidades mediadas pelo corpo (THIAGO, 2007; VARELA; THOMPSON; ROSCH, 1992). A interação epistemológica dos diversos povos acontece em virtude das trocas de experiências e conhecimentos veiculados não apenas nas apresentações orais, mas também na convivência dos estudantes e professores durante a etapa de estudos presenciais na universidade.

Ressaltamos que as discussões sobre os conceitos de "bilinguismo de transição e integração", "bilinguismo intercultural" e "interculturalidade crítica" tiveram destaque durante as aulas, uma vez que os discentes os identificaram como ferramentas de saber, seja pela dominação europeia colonial, seja em um período posterior, como forma de retomada ${ }^{9}$ de conhecimentos. Foi percebido, pelos alunos, que o "bilinguismo de transição", ao visar predominantemente à integração dos povos indígenas subalternizados à sociedade nacional, pautou-se em processos de escolarização impostos às custas de uma pedagogia externa, extremamente violenta e pretensamente superior, com vistas ao extermínio das cosmologias e conhecimentos indígenas, dado o processo de ocupação de terras para a expansão capitalista no Brasil. Por sua vez, o "bilinguismo intercultural" originado nas lutas dos povos indígenas, em um projeto social e político que objetivava questionar os pressupostos utilizados pela epistemologia eurocentrada para inferiorizar povos e conhecimentos indígenas, foi erigido a partir dos critérios raciais, linguísticos e religiosos dos vários povos. Quando chegamos às discussões sobre a "interculturalidade crítica", os alunos indicaram o conceito e sua prática como atitude que incide diretamente em suas vivências, pois este se fundamenta 
no fortalecimento identitário, na desocultação de conhecimentos hegemonicamente subalternizados e na retomada linguística e cultural dos povos indígenas.

As reflexões sobre esses conceitos, feitas por cada povo, fizeram emergir histórias e memórias durante as aulas, permitindo questionamentos e sugestões para que futuras propostas pedagógicas pudessem ser desenvolvidas nas aldeias.

\section{RESULTADOS E DISCUSSÃO}

\subsection{BILINGUISMO DE ASSIMILAÇÃO}

A tônica do documentário de Steven Heape e Chip Richie sintetiza-se na expressão reiteradamente mencionada "Matar o índio e salvar o homem". Apresenta inúmeros depoimentos de representantes dos povos indígenas dos Estados Unidos (Yuppie, Cheyenne, Chippewa, Cree, Navajo, Cherokee e Apache), egressos dos colégios internos cristãos. As narrativas demonstram práticas de evangelização e civilização agressivas e cruéis postas em prática pelo colonizador. A partir de 1840, com o ideário construído em torno do Destino Manifesto, ${ }^{10}$ os povos indígenas eram vistos como entrave ao expansionismo da civilização estadunidense e, em razão disso, deveriam ser expulsos de suas terras ou integrados plenamente à cultura do colonizador inglês.

Entre o final do século XIX e a primeira metade do século XX, a filosofia da educação indígena dos colégios internos estadunidenses tinha como objetivo principal extinguir os conhecimentos e as instituições ancestrais de meninos e meninas indígenas. Logo de início seus nomes foram mudados. A renomeação constituía-se como parte de todo um aparato cultural imposto a eles que, forçosamente, assumiam um nome e uma identidade cristã. Junto a isso, as crianças indígenas passavam pelo batismo como um símbolo do rompimento com seus conhecimentos originais, sendo-thes proibido, a partir de então, a comunicação na língua materna.

Ao mesmo tempo, eram obrigados a viver uniformizados, a desprenderem-se de todo conhecimento medicinal que haviam aprendido com seus pais ou avós e a adotar uma alimentação industrializada a que não estavam acostumados em suas aldeias. Por fim, eram conduzidos a sentir vergonha da cultura materna, em um processo gradual de ocultamento

10 'Em meio à 'corrida para o oeste', na metade do século XIX, surgiu uma expressão que iria marcar, senão a política da expansão, pelo menos o clima intelectual em que ela se dava. Tratava-se do 'Destino Manifesto', expressão jornalística que se popularizou rapidamente e que via a expansão territorial americana como um processo ilimitado, que não se deteria nas praias da Califórnia, mas avançaria pelo Pacífico afora e acabaria por dar a volta ao mundo! [...]. Antes mesmo que se iniciasse a expansão nos oceanos, já começavam a se formar o clima de opinião pública e as justificativas religiosas, culturais, políticas e econômicas da nova expansão." (MOURA apud MENDES, 2005, p. 171). 
e até de aniquilação de epistemologias, projetando a "erradicação completa de sua cultura e de quem eram." (NOSSOS ESPÍRITOS.., 2008).

Ao viverem grande parte da infância e adolescência nos colégios internos (cerca de oito a 12 anos), sob uma educação violenta e impositiva, no retorno para suas casas muitos estudantes vivenciavam um processo de estranhamento em suas comunidades, visto que os conhecimentos adquiridos para se formarem carpinteiros, ferreiros, pedreiros (formação dos meninos) e cozinheiras, faxineiras, costureiras e cuidadoras de crianças (formação das meninas) eram desnecessários para a vida em suas aldeias. Esse desajuste proporcionado pela educação assimilacionista nos Estados Unidos fez com que muitas crianças, ao "desaprenderem" a língua materna, retornassem para suas casas e passassem por um processo de estranhamento cultural cujos resultados, muitas vezes, foram o refúgio no alcoolismo, nas drogas, nos relacionamentos abusivos ou, até mesmo, no desencadeamento de distúrbios psiquiátricos.

Embora a educação indígena exposta no documentário envolva um contexto temporal mais prolongado que a experiência exposta no texto "A formação de trabalhadores brasileiros: a experiência do Colégio Isabel” (MARIN, 2009), os objetivos e resultados de ambos os projetos colonizadores se assemelham. No Colégio Isabel," a imposição da educação colonizadora ocorreu no contexto da expansão agropecuarista do Estado de Goiás durante a segunda metade do século XIX. Para escoamento da produção e ocupação de terras para pastagens seria fundamental a navegação pelo rio Araguaia como meio de comunicação fluvial entre o interior e o litoral do País. Contudo, os inúmeros povos indígenas concentrados no Vale do Rio Araguaia constituíam-se em um entrave aos projetos de navegação e ocupação da região, sendo, portanto, necessária uma intervenção educativa que transformasse as crianças indígenas em trabalhadores úteis para os projetos expansionistas do governo dessa unidade federativa. Voltar-se para as crianças indígenas era fundamental, pois elas eram vistas como tabula rasa, sendo pessoas que facilmente assimilariam os ensinamentos não indígenas, como os ideais cristãos e a educação ocidental, dois esteios colonizadores (MARIN, 2009, p. 156). Pelo rapto, compra, guerra ou ameaça de morte aos pais, muitas crianças indígenas ingressaram no Colégio lsabel, fundado por Couto de Magalhães, em 1870.

Todavia, uma distinção que podemos traçar em relação à educação dos colégios internos para os indígenas estadunidenses e dos colégios internos para os indígenas brasileiros situa-se no âmbito da língua materna. Para Couto de Magalhães, a língua deveria ser 
mantida para que se formassem intérpretes (DIAS, 2013), fundamentais para as conversações necessárias entre missionários, durante o processo de evangelização, e entre negociantes para as transações comerciais.

\begin{abstract}
Desejava-se transformar os índios, desde crianças, em instrumentos da produção econômica, por meio de uma educação que inculcasse uma outra racionalidade e uma outra religião, com a nítida intenção de ressocializá-los e torná-los instrumentos do processo de ocupação de novos territórios. (MARIN, 2009, p. 156).
\end{abstract}

A imposição cultural englobava práticas como o batismo e o uso de uniformes, alimentos e medicamentos não indígenas. Tanto em Goiás quanto nos Estados Unidos havia certo "privilégio" na educação voltada para os indígenas. Enquanto "[...] roupas, alimentação e medicamentos não eram fornecidos às escolas dos filhos da população civilizada - pelo menos com regularidade" (MARIN, 2009, p. 156) - e 80\% da população Cherokee era escolarizada, apenas $10 \%$ da população não indígena do entorno frequentava a escola. Um privilégio que denotava a intenção colonizadora de dominar a terra e as pessoas que nela viviam.

Outra similaridade encontra-se nos processos de subalternização a que foram envolvidos os estudantes nos dois contextos. "A pedagogia utilizada disseminou entre seus alunos o conceito de inferioridade da cultura indígena, para que eles se sentissem envergonhados de seu povo, de suas origens, de suas tradições e passassem a adotar traços dos modos de vida do homem civilizado." (MARIN, 2009, p. 156). A formação profissional constituiu-se em outro instrumento de subalternização dos estudantes. Os ofícios ensinados nessas escolas abrangiam apenas profissões situadas na escala inferior da sociedade, tanto para os meninos quanto para as meninas. Além disso, o ensino na língua colonizadora linglês ou português) era rudimentar. Poucos aprendiam efetivamente os ofícios e a língua ensinada, em decorrência da escolarização imposta e descontextualizada.

É importante ressaltar que, em ambos os casos, muitos estudantes indígenas não se submeteram aos objetivos colonizadores da escolarização:

No fim das contas essa política provou ser um sucesso e fracasso. Teve êxito ao educar o índio segundo os costumes dos brancos e ao minimizar por um tempo a língua e a cultura, mas fracassou na tentativa de eliminar as línguas indigenas, fracassou na tentativa de destruir essa cultura e fracassou na tentativa de assimilar os índios como homens brancos de pele vermelha. Por ironia, seu efeito foi dar aos índios as ferramentas necessárias para que estejam num patamar de igualdade, aprendam a lei e usam a lei para o bem de seu povo. (NOSSOS ESPÍRITOS..., 2008).

Além disso, 
[s]e o Colégio Isabel pretendia preparar crianças para assumir o modo de vida do colonizador, pode-se concluir que esse objetivo nem sempre foi possivel de alcançar. Alguns indigenas já se rebelavam contra seus superiores, mesmo ainda como internos no Colégio, seja pela fuga, seja por meio de atos de desobediência. No retorno às tribos, alguns alunos tomaram conhecimento dos problemas vividos por suas tribos e assumiram a luta contra o projeto dominante de subjugação e extermínio dos indígenas. (MARIN, 2009, p. 165-166).

Tais ações de rebeldia e fuga apontam para a luta pela sobrevivência dos conhecimentos e culturas ancestrais, principalmente visando à manutenção das suas línguas. Mesmo que longínquas no tempo, experiências semelhantes às do Colégio lsabel ainda permeiam a memória de muitos povos indígenas brasileiros, acessada por meio dos avós, sábios e anciãos nas aldeias, sendo narradas ações de fuga, isolamento e guerra.

Na apresentação oral realizada em sala de aula, os estudantes trouxeram elementos que corroboraram as práticas de escolarização impositivas dos agentes externos:

\begin{abstract}
Sabe-se que alguns parentes Guajajara passaram por coisas parecidas a do video. Segundo alguns anciões relatam que antigamente os padres vieram, e aos poucos foram conquistando os parentes, dando a eles vestimentos (sic), comida etc. E assim os padres foram se aproximando deles. Começaram a levar crianças indigenas com eles, dizendo que ia botar pra estudar, pra quando adulto serem alguém na vida: ser um doutor, professor, algo assim. Eles levavam as crianças, era só pra tirar as vidas delas, ou seja, matavam e assim, ia acabando com as crianças indigenas Guajajaras. Mãe (sic) das crianças perguntavam por elas e os padres falavam que as crianças estavam bem. Mas não retornavam com as crianças para as aldeias. (Estudantes Guajajará). ${ }^{2}$

No nosso povo o internato foi feito pelos missionários salesianos, teve características similares ao documentário e ao artigo. Relatos de nossos anciãos quando falavam a língua materna, eram mandado (sic) ficar de joetho no milho, amarrados ao mastro, na época que eram internos. Colocavam na cabeça dos internos bororos que a vida que tinham na aldeia não era boa, tinham que ter outra vida, vida de trabalho, tanto é que teve oficinas como resultado, teve olaria que constrói as casas, igreja, também oficina de carpintaria. Aos internos menores cuidar de animais domésticos, e as meninas aprendiam oficios domésticos - cozinha, corte e costura. Também as práticas dos Bororos não era (sic) de Deus. Como herança do gerenciamento dos missionários Salesianos predominou o ensino religioso. (Estudantes Bororo) (informações verbais).
\end{abstract}

Dadas as lutas dos povos indígenas pela escola bilíngue intercultural que culminaram, em 1988, nos direitos constitucionalmente garantidos, práticas de violência física e simbólica aliadas às tentativas de extinção das cosmologias indígenas têm sido rechaçadas no contexto nacional. No reconhecimento do Brasil como um país plurilíngue e pluridiverso,

Foi mantida a grafia original nas citações dos estudantes. 
os povos indígenas podem ter autonomia sobre seus processos de educação. Ainda que a escola seja uma instituição externa inserida na aldeia, ela passa a ser ressignificada por toda a comunidade, e não o contrário.

\subsection{EUIDENCIANDO A INTERCULTURALIDADE}

Após a leitura do texto "Interculturalidade: apontamentos conceituais e alternativa para a educação bilíngue" (NASCIMENTO, 2014) e debate, os discentes destacaram a existência de vivências interculturais, sobretudo com a sociedade não indígena. Em sua maioria são vivências negativas, relacionadas a conflitos com fazendeiros vizinhos às reservas indígenas, problemas relacionados ao desmatamento e à redução de animais nas áreas de mata das aldeias, diminuição da faixa de depleção dos rios e afluentes, ampliação da influência da alimentação industrializada no cotidiano indígena, diminuição de interesse pelos casamentos e outras festas tradicionais por parte das gerações mais novas, influência de missionários nas práticas tradicionais religiosas indígenas e aumento do suicídio entre os jovens. Todas essas vivências trouxeram mudanças nas práticas consideradas tradicionais, porém o contato com o não indígena permitiu também a ampliação dos meios de comunicação e a possibilidade de expansão de conhecimentos. Seja frequentando uma universidade, seja comunicando-se com outros povos indígenas do Brasil, distantes territorialmente, o contato via telefones celulares e internet também permitiu o fortalecimento de alguns traços culturais de alguns povos e mudanças em outros.

Aspectos como a pintura corporal, a língua e o canto tradicional podem receber influências de outros povos indígenas, caso haja interesse da própria cultura por elas. Em relação à língua, por exemplo, o povo Yawalapiti recebeu influência de várias culturas, por isso, mesmo pertencendo à família Arawak, compreendem as línguas de origem Karibe (língua Kuikuro), Tupi e Portuguesa. 0 caráter intercultural entre povos indígenas também se evidencia por meio dos intercâmbios, ou seja, pelas trocas culturais. Além de visitas a outros povos, há trocas de conhecimentos nas festas e jogos entre as aldeias visitada e visitante. No final de 2017, por exemplo, os Xavantes fizeram um intercâmbio no Xingu.

Nas narrativas dos discentes ficou evidente a intensificação do uso das tecnologias nas comunidades indígenas como forma positiva de mudança. 0 uso dos recursos tecnológicos (eletrodomésticos como fogão, geladeira, televisão e aparelho celular) proporcionou aos povos indígenas experimentar várias situações que thes beneficiam, como a possibilidade do registro filmico de festas ou rituais para "gravar na memória", acompanhar os acontecimentos e notícias sobre o País, conservar alimentos, comunicar-se com amigos ou parentes, e, ainda, para pesquisas e estudos acadêmicos. 
No âmbito escolar, pode-se dizer que não existem mais imposições realizadas por missionários ou outros líderes religiosos, porém outras instituições assumem esse papel. As Secretarias de Educação promovem uma política de educação diferenciada, entretanto em muitos relatos são evidenciadas a não execução ou a liberdade de exercício desse direito. Nesse sentido, as tecnologias têm sido grandes aliadas na educação, permitindo aos professores e às lideranças conhecer seus direitos e lutarem pelos espaços diferenciados.

Por outro lado, esses mesmos recursos interferem negativamente, segundo os estudantes indígenas, na dinâmica interna das aldeias: enfraquecem aspectos culturais, entre eles a diminuição da contação de histórias. Entre os povos do Alto Xingu, o momento em que os avós contavam histórias às crianças era o horário de dormir, substituído hoje por assistir à televisão. Além disso, a cultura passa por um processo de adormecimento, ou seja, as pessoas conhecem a cultura, mas não a praticam. Isso interfere no comportamento dos jovens, que perdem a vontade de ouvir histórias ou de ir para a escola em razão do envolvimento com as redes sociais, possibilitada pelo uso do aparelho de celular; além disso, a postura corporal se modifica pelo uso constante desses aparelhos. Muitos jovens ficam com os "ombros caídos", afirmam os estudantes. Todavia, a influência mais danosa da tecnologia nas aldeias é o aumento do índice de suicídio entre os indígenas. Entre os $\ln \tilde{y}{ }^{13}$ o assunto tem provocado debate com as lideranças, visto que a incidência do suicídio entre os jovens é elevada nos últimos anos, segundo ponderações dos estudantes Karajá e Javaé.

Apesar de todos esses pontos negativos indicados, um dado interessante destacado pelos estudantes durante a apresentação foi o posicionamento decolonial assumido por eles, entendendo-se por decolonial suas atitudes de resistência e desobediência ontológica e epistêmica frente às imposições da sociedade envolvente. Os Bororos revelaram uma importante prática da oralidade, o bakaru, cuja intenção é subalternizar o que foi escrito por historiadores e antropólogos, ou seja, inverter a situação de colonialidade proporcionada pela escrita não indígena. Aliada a essa prática está a contação de histórias às crianças pelos anciãos Bororo, algo que difere da prática da leitura, visto que na narração oral acontece a contextualização da história com a inserção dos barulhos que dela fazem parte, diferentemente da escrita, na qual "não se ouve nada", eles afirmam.

Com a mesma perspectiva, os estudantes Xavante abordaram a Constituição Federal de 1988 como um marco na garantia dos direitos dos povos indígenas e também como prática da decolonialidade. Em suas palavras, "antes a ideia era colonizar, agora os indígenas têm que decolonizar." Com esse princípio, eles apresentaram estratégias adotadas nas aldeias Xavante para fortalecer a cultura ancestral, como, por exemplo, a adoção de restrições em campeonatos de futebol e ao ato de assistir televisão. 0 critério para integrar o 
campeonato é a participação na corrida de tora e o para participar das danças tradicionais é deixar de ver novelas. São estratégias discutidas e aprovadas pela comunidade visando ao fortalecimento cultural dos Xavante.

Destarte, percebemos que a transdisciplinaridade (MATURANA, 2000), práxis existente no cotidiano indígena, em seus conhecimentos e cosmologias, prescinde do parcelamento disciplinar característico da episteme ocidental. Por isso, as abordagens feita em suas narrativas e vivências incluem experiências em sua totalidade, desde as histórias de origem do povo até as abrangentes demandas atuais, como questões sociais e econômicas, problemas na área da educação e conflitos por terras. Consideramos que a transdisciplinaridade é um saber indígena, muito antes de este ser ou estar em evidência nos nossos meios acadêmicos e escolares nos dias atuais.

\subsection{PRÁXIS INTERCULTURAL}

Ontologicamente, ser indigena inclui a inseparabilidade entre cultura e natureza, corpo e mente, seres visíveis e invisíveis, algo que extrapola o conhecimento disciplinar típico da racionalidade ocidental, algo plenamente perceptível na terceira e última atividade didática realizada com os discentes: debater e demonstrar a interculturalidade no cotidiano das aldeias indígenas, oriunda da incorporação de práticas culturais pertencentes a outros povos indígenas ou mesmo de práticas incorporadas ou impostas por hábitos culturais dos não indígenas. Nessa atividade e nas anteriores, ficou claro que a interculturalidade pode tanto possibilitar o entendimento entre povos, o enriquecimento e o fortalecimento de culturas, quanto o desentendimento ou a imposição de práticas não tradicionais e destrutivas às existentes.

Entre o povo Bororo, o Mekugo Epewa Akadureu (ornamento corporal) era feito de fibra vegetal, contudo, após o contato com a cultura não indígena, o ornamento passou a ser feito de algodão (Akigo), matéria-prima até então desconhecida por eles. No texto redigido pelos estudantes é mencionado que cada clã adota uma cor (ou mistura de cores) para se diferenciarem entre si:

\footnotetext{
Akigo é um ornamento cultural, teve incorporação de elementos culturais (materiais do povo não indígena), era extraído da fibra de ritowo, contudo, ao ser descoberta a linha de algodão e ter cores conforme a nossa cultura, passou a ser usada. Contudo, sem perder a originalidade e essência. Cada Akigo representa um clã e sub-clã, serve de identidade e traz significados. Quando há Bue Moridado, quem vinga a morte recebe do falecido direito a usar os enfeites do clã e Akigo também. (Estudantes Bororo) (informação verbal).
}

A manutenção de valores relacionados aos clãs se mantém, mesmo havendo mudanças nas matérias-primas utilizadas. 


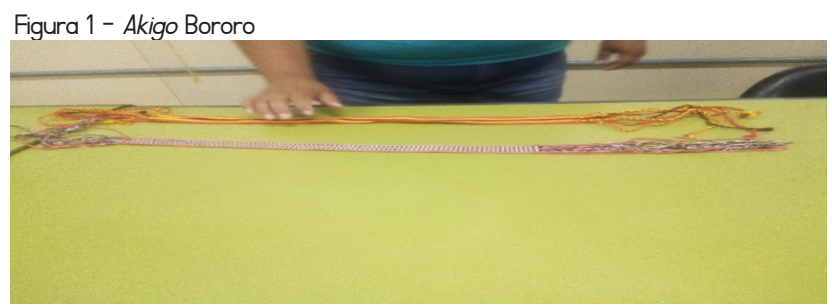

Fonte: os autores.

Entre o povo Xavante, o uso dos adornos 'Wamnhõrõ, que consiste em uma vestimenta utilizada em muitos ritos, tem ficado escasso. 0 desmatamento intensivo dos territórios indígenas e o não acesso a muitas espécies vegetais fez com que buscassem substitutos para a feitura da ornamentação dessa vestimenta, sendo o principal deles a miçanga. Hoje compram na cidade miçangas coloridas, que atualmente compõem a parte frontal da vestimenta. Tal uso de elementos externos à cultura Xavante demonstra uma das maneiras atuais de articulação intercultural.

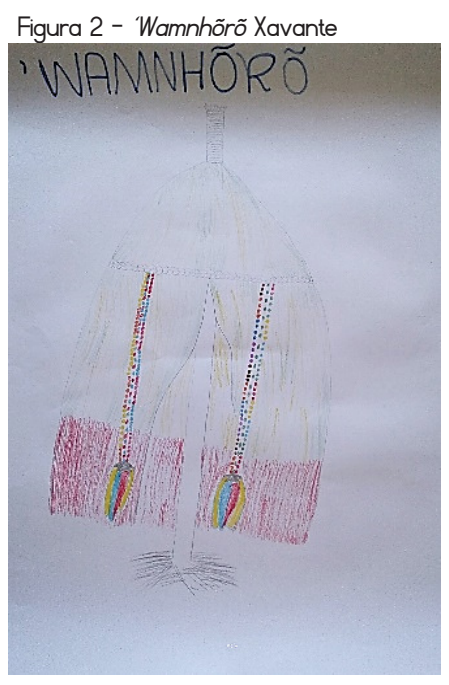

Fonte: os autores.

Além da vestimenta, o grupo apresentou música e dança inspiradas nas manifestações tradicionais dos povos do Xingu. Tanto a música quanto a dança foram estilizadas, buscando representar uma estética de povos indígenas amazônicos, o que causou certo incômodo entre os indígenas xinguanos presentes. Hoje, essa forma de apresentação faz parte da cultura Xavante e também representa um dos elementos interculturais desse povo. 
Entre os Xerente está presente, em algumas festas, além da corrida de tora, a corrida de flecha, uma prática introduzida por outros povos indígenas e que passou a ser uma manifestação cultural desse povo. Reconhecem a força dessa manifestação na atualidade e como elemento intercultural. Muito diferente é a situação Guajajara, em que pastores e grupos religiosos cristãos (Karaiw máe) adentram cada vez mais as aldeias. Os pastores traduzem e ensinam as músicas evangelizadoras na língua portuguesa e na língua indígena como forma de assimilação mais eficiente da cultura cristã. Dessa maneira, a religião indígena (Jentehar ma'e) enfraquece, assim como vários outros elementos da cultura, como festas e ritos. Apesar da presença dos grupos cristãos nas aldeias, a língua e outras manifestações permanecem vivas, como rituais e práticas alimentares.

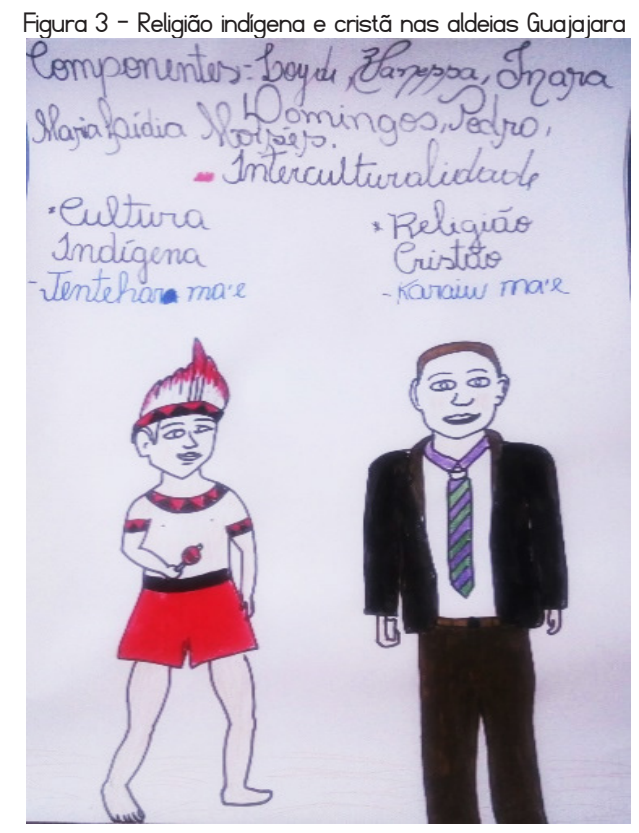

Fonte: os autores.

Entre os Javaé, o Woú, um rito Tapirapé, está presente em razão das circunstâncias de contato entre os dois povos. A presença de tal rito indica a existência da interculturalidade muito anterior ao contato com os não indígenas. Do mesmo modo, entre os Tapirapé, o Xiwexiwe é uma de suas manifestações religiosas que recebeu influências Javaé em vestimentas, adornos, música e dança. 0 contato muito próximo dos dois povos proporcionou as semelhanças e o intercâmbio cultural. Entre os povos Gavião, a pintura e os adornos de outros povos (Amazônicos e da llha do Bananal) passaram a ser usados em rituais, como, por exemplo, nos casamentos. Estes, por sua vez, também tiveram sua 
estrutura modificada. Se antes os noivos não eram acompanhados de parentes durante o rito, atualmente há "padrinhos" que os acompanham, principalmente a noiva. Tal intercâmbio intercultural ocorreu em razão do contato com os casamentos cristãos dos não indígenas de maneira mais frequente na atualidade.

Nas aldeias Krahô tem sido cada vez mais frequente a celebração da formatura do $3^{\circ}$ ano do Ensino Médio escolar, seguida de festa tradicional, como maneira de reconhecer os estudantes formados na aldeia. Esta consiste em uma maneira de ressignificar e reconhecer o esforço dos estudantes que finalizaram essa etapa escolar na aldeia e firmar que, a partir de então, estão preparados para seguir para um curso universitário, constituir liderança e fortalecer a identidade do povo. Ao invés de uma cerimônia com becas, diplomas e palco, ocorre uma festa com música, canto, pinturas e ornamentos Krahô. Os formandos são acompanhados pelo ancião ao centro da aldeia (cá) como maneira de reforçar seu pertencimento no grupo.

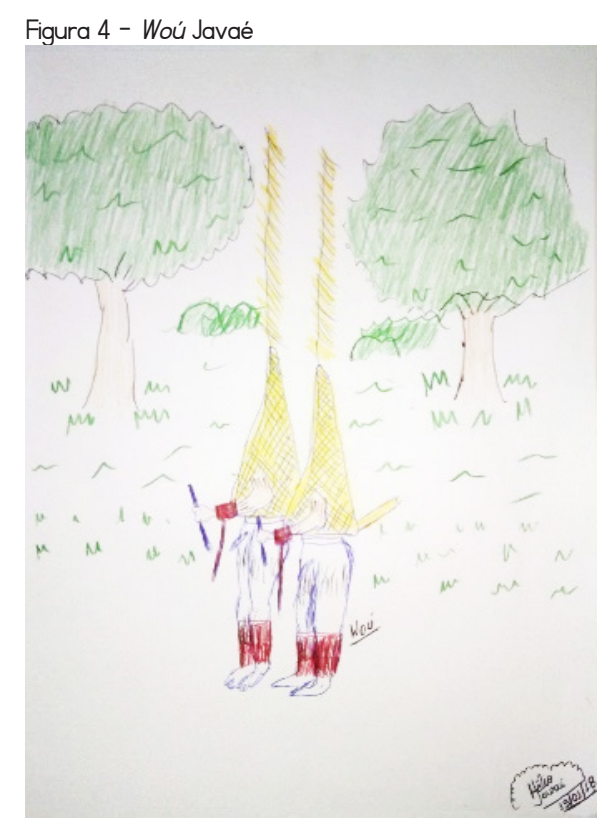

Fonte: os autores.

A atividade de pesca entre os Karajá é essencial para a sobrevivência, além de possuir significações cosmológicas para esse povo. 0 uso de instrumentos e técnicas não indígenas, como as redes de pesca nos rios, têm prejudicado cada vez mais a diversidade da ictiofauna (conjunto das espécies de peixes existentes em determinada região, no caso, no rio Araguaia). Os antigos arco e flechas deixaram de ser usados, inclusive pelos indígenas, que sentem os impactos negativos dessa mudança durante o contato com os não indígenas. 
A decolonialidade se torna, assim, uma arma para a conscientização e o fortalecimento dos saberes tradicionais, incentivada cada vez mais pelos professores indígenas nas aldeias.

Entre os Kayapó, adornos corporais considerados tradicionais na atualidade passaram por mudanças em sua feitura, principalmente quanto ao uso da matéria-prima. Um cocar originalmente feito de penas amarelas é confeccionado, na atualidade, com penas pintadas para que fiquem com essa cor, uma vez que o pássaro do qual eram extraídas não é mais encontrado na área da reserva de sua aldeia pelo desmatamento intensivo. Além deste, um colar originalmente feito com sementes foi modificado, sendo usadas miçangas no lugar das sementes e armação de metal. Ainda se tratando de artesanato, os povos do Alto Xingu (Kalapalo, Yawalapiti e Kuikuro) apresentaram à turma pinturas da cerâmica que hoje fazem parte das pinturas utilizadas por seus povos nos ritos, mas que são originárias dos povos Waurá e Mehinako.

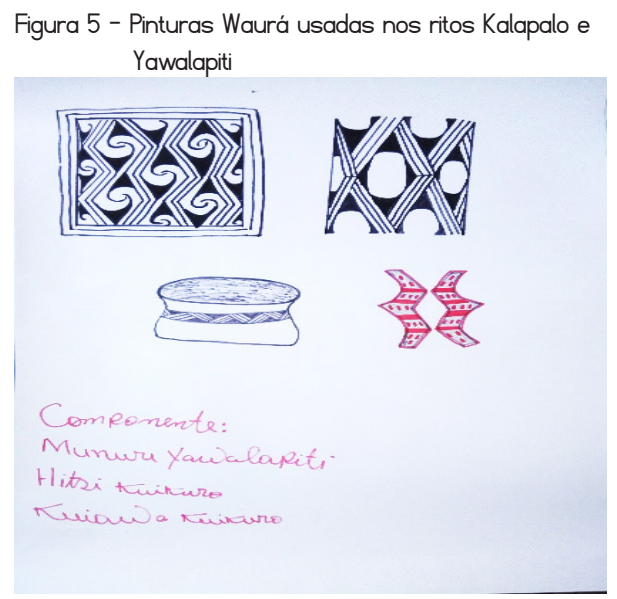

Fonte: os autores.

Consideramos que o chamado "intercâmbio entre povos" (termo usado pelos próprios indígenas durante a aula) já existia como prática antes mesmo de ser utilizado nas políticas públicas atuais. Avaliamos, ainda, que a atividade proporcionou diversas reflexões a respeito do cotidiano dos alunos nas suas aldeias e pôde, assim, estender-se para outros âmbitos de suas vidas sociais e acadêmicas. Como instrumento de estudo e pesquisa, o "intercâmbio entre povos" permitiu, possivelmente, novas reflexões para a construção de novas didáticas, que poderão ser aplicadas dentro e fora das salas de aula das aldeias.

\section{CONSIDERAÇÕES FINAIS}


Os princípios curriculares da transdisciplinaridade e da interculturalidade, aqui entendidos "de forma dialógica, tanto no que se refere à relação entre as diferentes culturas quanto à interação entre as várias áreas do saber" (UNIVERSIDADE FEDERAL DE GOIÁS, 2011, p. 33), proporcionam uma relação de continuidade entre elas "sem separar, por exemplo, matemática de geografia, línguas de história, literatura de arte." (UNIVERSIDADE FEDERAL DE GolÁS, 2011, p. 33). São eles os princípios constituidores do Curso de Licenciatura em Educação Intercultural da UFG, que buscam, por meio dessa concepção, permitir que a postura didática transdisciplinar e intercultural aconteça normalmente.

A transdisciplinaridade faz parte do cotidiano indigena, visto que, em suas cosmologias, o conhecimento prescinde do parcelamento disciplinar característico da episteme ocidental, por isso, nas apresentações feitas em sala de aula, os assuntos foram tratados sem restrição ou pertencimento à determinada disciplina. A transdisciplinaridade possibilitou a compreensão ampla dos conhecimentos pelos povos indigenas, visto que os temas abordados apontam para diversos assuntos, incluindo as cosmologias indigenas como partícipe primordial de suas epistemes.

Discutir a interculturalidade crítica como projeto e como atitude incide diretamente na vivência dos estudantes do Curso de Educação Intercultural, pois este se fundamenta no fortalecimento identitário, na desocultação de saberes hegemonicamente subalternizados e na retomada linguistica e cultural dos povos indigenas. Ressalta-se a relevância desse tema contextual, trabalhado 10 anos após o início do curso de formação de professores indígenas, em 2007, para o debate em torno das categorias básicas do tema: transdisciplinaridade e interculturalidade crítica.

Restringir os processos de aprendizagem à exposição conteudista, à leitura de textos e ao debate de temáticas concernentes aos povos indígenas impõe limites às possibilidades de aprendizados interculturais que o contexto do Curso evidencia, como, por exemplo, a interação epistemológica dos diversos povos em sala de aula em virtude das trocas de experiências e conhecimentos veiculados não apenas nas apresentações orais, mas também na convivência dos estudantes e professores durante a etapa de estudos presenciais na UFG.

Dessa forma, planejar e replanejar propostas didáticas adequadas ao tema contextual Educação Bilingue Intercultural faz-se sempre necessário para que as epistemologias indigenas permeiem todas os dias de aula, bem como um posicionamento didático que vai ao encontro da interculturalidade crítica (WALSH, 2013; WALSH; VIAÑA; TAPIA, 2010), ao ter como uma de suas perspectivas a visibilidade dos povos indígenas no contexto social, educacional, politico e cultural brasileiro. 
Ao final do tema contextual, os alunos avaliaram as atividades e as aulas realizadas, mencionando o que permitiu mais reflexões para seus contextos como educadores ou futuros educadores. De maneira geral, referiram-se às atividades como importantes pontos para abertura de reflexões, pois os novos conceitos e terminologias apresentados abriram possibilidades de busca de outros caminhos para pensar o fazer docente. Além disso, apontaram que as aulas trouxeram à memória práticas que poderão ser realizadas como atividades culturais nas salas de aulas de suas aldeias e também nos pátios e nos momentos festivos. Os saberes tradicionais - como a dança, a música, a língua materna, a produção de artesanatos, as pinturas e as atividades de caça e pesca -, assim como as atividades ritualísticas, possuem, em maior ou menor grau, relações intensas e influências das atividades não indígenas, mas o saber e o fazer podem caminhar lado a lado no envolvimento das crianças e jovens da comunidade. Isso para que todas essas fontes de conhecimento locais não se constituam somente em memória e parte do passado. Como docentes, analisamos que aulas com dinamicidade de atividades permitem a participação mais intensiva e envolvem de maneira mais efetiva os discentes, permitindo reflexões e a participação ativa não apenas em sala de aula, mas também em seus contextos sociopolíticos universitário e comunitário.

0 exercício de construção de conhecimentos em conjunto permitiu a ampliação de práticas e saberes, uma vez que a práxis não se limita à docência ou ao docente, ela é abrangente, extensiva e contínua. Os conceitos abordados puderam trazer mais que reflexões, permitiram a visualização de caminhos para pensar ações e posturas decolonizadoras nas várias aldeias.

\section{REFERÊNCIAS}

CANDAU, V. M. F. Educación intercultural en América Latina: distintas concepciones y tensiones actuales. Estudios Pedagógicos 36, n. 2, p. 343-352, 2000.

CANDAU, V. M. F.; RUSSO, K. Interculturalidade e educação na América Latina: uma construção plural, original e complexa. Revista Diálogo Educação, Curitiba, v. 10, n. 29, p. 151-169, jan./abr. 2010.

DIAS, T. C. Contatos e desacatos: os línguas na fronteira entre sociedade colonizadora e indígenas (1740 a 1889) - Goiás. Espaço Ameríndio, Porto Alegre, v. 7, n. 2, p. 205-226, jul./dez. 2013.

MALDONADO-TORRES, N. Transdisciplinaridade e decolonialidade. Revista Sociedade e Estado, v. 31, n. 1, p. 75-97, 2016.

MARIN, J. O. B. M. A formação de trabalhadores brasileiros: a experiência do Colégio Isabel. História Unisinos, n. 13, v. 2, p. 154-167, maio/ago. 2009. 
MATURANA, H. Transdisciplinaridade e cognição. In: CETRANS (org.). Educação e Transdisciplinaridade. 1. ed. UNESCO. São Paulo: TRIOM, 2000. p. 79-110.

MENDES, R. A. S. América Latina - interpretações da origem do imperialismo norte-americano. Projeto História, São Paulo, n. 31, p. 167-188, dez. 2005.

NASCIMENTO, A. M. Interculturalidade: apontamentos conceituais e alternativa para a educação bilíngue. Revista Sures, n. 3, 2014. Disponivel em: https://revistas.unila.edu.br/index.php/sures/article/ view/१२१/१२7. Acesso em: dez. 2014.

NAZARENO, E. História, tempo e lugar entre o povo indígena Bero Biawa Mahãdu (Javaé): a partir da interculturalidade crítica, da decolonialidade e do enfoque enactivo. In: OLIVEIRA, M. J. (org.). Direitos humanos e pluriversalidade: conexões temáticas. 1. ed. Curitiba: Editora Prismas Ltda, 2017. p. 85-118.

NAZARENO, E;; ARAÚJO, 0. C. G. Reflexões em torno do tema contextual "Etnicidade e diversidade cultural". Revista Articulando e construindo saberes, Goiânia, v. 2, n. 1, 2017.

NOSSOS ESPÍRITOS não falam inglês: internato indigena. Direção: Chip Richie, Produção: Steven Heape. [Estados Unidos: s. n.], 2008. 1 vídeo (52 min.).

PIMENTEL DA SILVA, M. do S. A pedagogia da retomada: decolonização de saberes. Articulando e Construindo Saberes, Goiânia, v. 2, n. 1, p. 204-216, 2017.

PIMENTEL DA SILVA, M. do S. As línguas indígenas na escola: da desvalorização à revitalização. Signótica, v. 18, n. 2, p. 381-395, jul./dez. 2006.

PIN, A. E. História da educação do povo Javaé: do período colonial à República. Dissertação (Mestrado em História) - Universidade Federal de Goiás, Goiânia, 2014.

REPETTO, M. Os sentidos das fronteiras na transdisciplinaridade e na interculturalidade. Textos \& Debates, Boa Vista, n. 22, p. 13-30, jul./dez. 2012.

STELL, C. A.; CARVALHO, I. C. M. Epistemologias ecológicas: delimitando um conceito. Mana: Estudos de Antropologia Social, n. 20, v. 1, p. 163-183, 2014.

THIAGO, E. M. C. P. S. 0 texto multimodal de autoria indígena: narrativa, lugar e interculturalidade. Tese (Doutorado em Estudos Linguísticos e Literários em Inglês) - Universidade de São Paulo, São Paulo, 2007.

UNIVERSIDADE FEDERAL DE GOIÁS. Projeto Político Pedagógico. Licenciatura Intercultural. Goiânia: UFG, 2011.

VARELA, F. J.; THOMPSON, E.; ROSCH, E. De cuerpo presente: las ciencias cognitivas y la experiencia humana. Barcelona: Editorial Gedisa, 1992.

WALSH, C. (org.). Pedagogías decoloniales: prácticas insurgentes de resistir, (re)existir y (re)vivir. Tomo I. Quito-Ecuador: Ediciones Abya-Yala, 2013. p. 23-68. 
WALSH, C.; VIAÑA J.; TAPIA, L. Interculturalidad crítica y educación intercultural. Bolivia: Instituto Internacional de Integración, 2010. p. 75-96.

Endereços para correspondência: Rua 1044, n. 129, Setor Pedro Ludovico, 74825-110, Goiânia, Goiás; tamirismaia_19@hotmail.com 
